\title{
Primary adenocarcinoma of the duodenum associated with cutaneous neurofibromatosis (von Recklinghausen's disease)
}

\author{
J. J. MCGLinCheY† \\ F.R.C.S.I.
}

\author{
G. J. SANTER $\dagger$ \\ F.R.C.S.
}

\author{
M. T. HAQQANI* \\ D.Path., M.R.C.Path.
}

Departments of $\uparrow$ Surgery and ${ }^{*}$ Histopathology, Walton Hospital, Rice Lane, Liverpool L9 1 AE

\begin{abstract}
Summary
A case of primary adenocarcinoma of the duodenum in a 29-year-old man with neurofibromatosis (von Recklinghausen's disease) is described. As far as can be ascertained, such an association has not been described before.

Introduction

The association of neurofibromatosis with malignant tumours of the neural crest is well documented. Neurofibromatosis may also be associated with other malignant tumours such as carcinoid of the ampulla of Vater (Barber, 1976), adenocarcinoma of the pancreas (Kellar and Logan, 1977), adenocarcinoma of the colon (Jenkins and Gill, 1972), Wilms' tumour (Stay and Vauter, 1977), rhabdomyosarcoma (McKeen and Bodurtha, 1978) and leukaemia (Bader and Miller, 1978). The authors wish to report the association of primary adenocarcinoma of the duodenum in a young man suffering from cutaneous neurofibromatosis.
\end{abstract}

\section{Case report}

A 29-year-old man was admitted for removal of neurofibromas from his back. Examination revealed him to be clinically jaundiced with an 8-cm hepatomegaly. Significant laboratory findings included a bilirubin of $12.6 \mu \mathrm{mol} / \mathrm{l}$ and an alkaline phosphatase of $364 \cdot 23 \mathrm{u}$./l. Chest X-ray was normal.

A percutaneous transhepatic cholangiogram showed the common bile duct to be obstructed in the region of the ampulla of Vater. Several cutaneous neurofibromas were excised, and confirmed histologically.

Laparotomy was performed and a circumscribed lesion of the ampulla of Vater measuring $2 \times 2 \times 1$ $\mathrm{cm}$ removed with formation of a choledocoduodenostomy. Histologically, the lesion proved to be a

Reprint requests to $\mathrm{Dr} M$. T. Haqqani. primary adenocarcinoma of the duodenum which was incompletely excised. Re-exploration was performed one month later and a $15-\mathrm{cm}$ segment of proximal small bowel with a portion of the head of the pancreas measuring $5 \times 4 \times 3 \mathrm{~cm}$ was removed (Whipple's pancreatico-duodenectomy). The ampulla of Vater was raised owing to a polypoid tumour measuring $2.5 \times 1 \times 1 \mathrm{~cm}$. Four regional lymph nodes were enlarged.

Histology showed a well differentiated adenocarcinoma of the duodenum (Fig. 1) infiltrating deep into the muscular layer. The columnar epithelium of the adjacent duodenal glands was hyperplastic, with hyperchromatism, mild pleomorphism and atypical changes of the epithelial cells. These changes appeared to merge with areas of well differentiated adenocarcinoma suggesting a primary origin of the malignancy within the duodenum. The epithelium of the terminal common bile duct also showed stratification, some pleomorphism and atypical changes suggestive of involvement by a wide field neoplastic change. Invasive carcinoma of the bile duct was not found. All the 4 lymph nodes were infiltrated by a well differentiated metastatic adenocarcinoma.

Postoperatively the patient developed a pancreatic fistula which required 7 weeks of i.v. alimentation. He took his own discharge from hospital 9 weeks postoperatively and never returned for follow-up. He died at home 2 months later. A post-mortem was not performed.

\section{Discussion}

Primary adenocarcinoma of the duodenum is rare, $17 \%$ of such tumours are peri-ampullary, the remainder are evenly distributed above and below the ampulla (Lillimoe and Imbembo, 1980). The peak age incidence is in the sixth and seventh decades. 


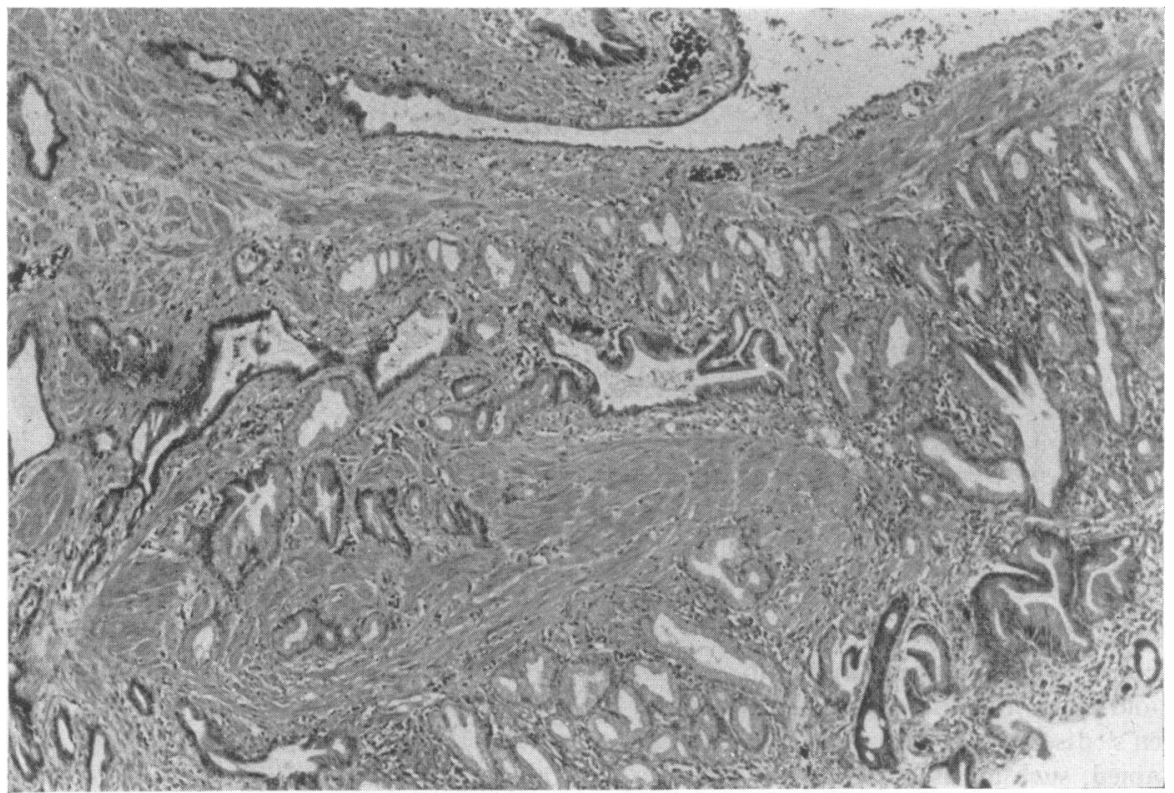

Fig. 1. A well differentiated adenocarcinoma of the duodenum infiltrating into the muscular layer $(\mathrm{HE}, \times 125)$.

It has been suggested that the gene for neurofibromatosis increases the risk for a multiplicity of malignancies (Hecht and McGaw, 1979), the incidence of associated malignancies being from $3 \%$ to $15 \%$ (Keller and Logan, 1977). The authors are unaware of any other reported cases of duodenal carcinoma associated with neurofibromatosis.

Surgical resection produces the best results in duodenal carcinoma. Segmental resection is preferred for localized lesions. More radical procedures would not appear to improve the 5-year survival rate of 20-25\% (Hecht and McGaw, 1979; Spira, Ghazi and Wolff, 1977; Pagtalunan, Mayo and Dockerty, 1964). It has been suggested that the tumours are radiosensitive and a prolonged survival rate was noted in 4 patients who had palliative bypass procedures and radiotherapy (Sakker and Ware, 1973).

\section{References}

BADER, J.L. \& MilleR, R.W. (1978) Neurofibromatosis and childhood leukemia. Journal of Pediatrics, 92, 925.
BARber, P.V. (1976) Carcinoid tumour of the ampulla $\frac{8}{\mathrm{f}} \overrightarrow{\mathrm{c}}$ Vater associated with cutaneous neurofibromatoss. Postgraduate Medical Journal, 52, 514.

Heснт, F. \& MCGAW, B.K. (1979) Neurofibromatosis andd malignancy (Letter). Journal of Pediatrics, 94, 1010.

JENKINS, D.H.R. \& GiLl, W. (1972) A case of carcinoma of the colon in association with neurofibromatosis. British Journal of Surgery, 59, 322.

KelleR, P.V. \& LogAN, G.M. (1977) Adenocarcinoma of the pancreas associated with neurofibromatosis. Cancer, 39, 1264.

Lillimoe, K. \& ImвEмвo, A.L. (1980) Malignant neoplasms 3 of the duodenum. Surgery, Gynecology and Obstetrics,

McKeen, E.A. \& Bodurtha, J. (1978) Rhabdomyosarcoma complicating neurofibromatosis. Journal of Pediatrics, 93, 992.

Pagtalunan, R.J.G., Mayo, C.W. \& Dockerty, M.B.o (1964) Primary malignant tumors of the small intestines, American Journal of Surgery, 108, 13.

SAKKER, S. \& WARE, C.C. (1973) Carcinoma of the duodenum, 윽 comparison of surgery, radiotherapy and chemotherapy. British Journal of Surgery, 60, 867.

Spira, I.A., Ghazi, A. \& WolfF, W.I. (1977) Primary adenocarcinoma of the duodenum. Cancer, 39, 1721.

STAY, E.J. \& VAUTER, G. (1977) The relationship between nephroblastoma and neurofibromatosis. Cancer, 39, 2550. N 